\title{
Isobaric tags for relative and absolute quantitation-based proteomics reveals potential novel biomarkers for the early diagnosis of acute myocardial infarction within $3 \mathrm{~h}$
}

\author{
CHANGQING DU ${ }^{1,2^{*}}$, YINGZHENG WENG ${ }^{3 *}$, JIANGJIE LOU ${ }^{3}$, GUANGZHONG ZENG $^{4}$, \\ XIAOWEI LIU ${ }^{1}$, HONGFENG JIN ${ }^{1}$, SENNA LIN ${ }^{2}$ and LIJIANG TANG ${ }^{1-3}$ \\ ${ }^{1}$ Department of Cardiology, Zhejiang Hospital, Hangzhou, Zhejiang 310013; ${ }^{2}$ Department of Medicine, \\ The Second College of Clinical Medicine, Zhejiang Chinese Medical University, Hangzhou, Zhejiang 310053; \\ ${ }^{3}$ Department of Medicine, School of Medicine, Wenzhou Medical University, Wenzhou, Zhejiang 325035; \\ ${ }^{4}$ Department of Cardiology, Pingxiang City People's Hospital, Pingxiang, Jiangxi 337055, P.R. China
}

Received September 9, 2018; Accepted March 4, 2019

DOI: $10.3892 /$ ijmm.2019.4137

\begin{abstract}
Acute myocardial infarction (AMI) is one of the most common and life-threatening cardiovascular diseases. However, the ability to diagnose AMI within $3 \mathrm{~h}$ is currently lacking. The present study aimed to identify the differentially expressed proteins of AMI within $3 \mathrm{~h}$ and to investigate novel biomarkers using isobaric tags for relative and absolute quantitation (ITRAQ) technology. A total of 30 beagle dogs were used for establishing the MI models successfully by injecting thrombin powder and a polyethylene microsphere suspension. Serum samples were collected prior to $(0 \mathrm{~h})$ and following MI (1, 2 and $3 \mathrm{~h}$ ). ITRAQ-coupled liquid chromatography-mass spectrometry (LC-MS) technology was used to identify the differentially expressed proteins. The bioinformatics analysis selected several key proteins in the initiation of MI. Further analysis was performed using STRING software. Finally, western blot analysis was used to evaluate the results obtained from ITRAQ. In total, 28 proteins were upregulated and 23 were downregulated in the $1 \mathrm{~h} / 0 \mathrm{~h}$ group, 28 proteins were upregulated and 26 were downregulated in the $2 \mathrm{~h} / 0 \mathrm{~h}$ group, and 24 proteins were upregulated and 19 were downregulated in the $3 \mathrm{~h} / 0 \mathrm{~h}$ group. The Gene Ontology (GO) annotation and functional enrichment analysis identified 19 key proteins. Protein-protein interactions (PPIs) were investigated using the STRING database. GO enrichment analysis revealed that a number of key proteins, including ATP synthase F1 subunit $\beta$
\end{abstract}

Correspondence to: Dr Lijiang Tang, Department of Medicine, School of Medicine, Wenzhou Medical University, 82 XuanYuan West Road, Lucheng, Wenzhou, Zhejiang 325035, P.R. China E-mail: zjyytang@163.com

*Contributed equally

Key words: proteomics, isobaric tags for relative and absolute quantitation, acute myocardial infarction, beagle, biomarkers
(ATP5B), cytochrome $c$ oxidase subunit 2 and cytochrome $c$, were components of the electron transport chain and were involved in energy metabolism. The western blot analysis demonstrated that the expression of ATP5B decreased significantly at all three time points $(\mathrm{P}<0.01)$, which was consistent with the ITRAQ results, whereas the expression of fibrinogen $\gamma$ chain increased at 2 and $3 \mathrm{~h}(\mathrm{P}<0.01)$ and the expression of integrator complex subunit 4 increased at all three time points $(\mathrm{P}<0.01)$, which differed from the ITRAQ results. According to the proteomics of the beagle dog MI model, ATP5B may serve as the potential biomarkers of AMI. Mitochondrial dysfunction and disruption of the electron transport chain may be critical indicators of early MI within $3 \mathrm{~h}$. These finding may provide a novel direction for the diagnosis of AMI.

\section{Introduction}

At present, acute myocardial infarction (AMI) is one of the most life-threatening diseases worldwide (1). Therefore, the prompt diagnosis of AMI is critical for rescuing cardiomyocytes and improving patient survival. However, several deficiencies in the diagnosis of MI remain. In the early-stage of AMI, most patients do not present with typical signs, and $50 \%$ of the patients do not present with specific electrocardiogram (ECG) changes (2). Currently, the most rapid and effective estimation of MI is the detection of biochemical markers. Cardiac troponin I (cTnI) and creatine kinase isoenzyme (CK-MB) are the most widely used biomarkers in the clinic. Although the sensitivity and specificity of these indices are acceptable, the value in the diagnosis of AMI within $3 \mathrm{~h}$ remains limited (3-5). Therefore, the identification of biomarkers that can reflect the specificity of early MI within $3 \mathrm{~h}$ is under intensive focus.

The isobaric tags for relative and absolute quantitation (ITRAQ) method is an efficient technique that examines the biomarkers of various diseases developed by AB SCIEX (6). The technology uses four or eight isotopic reagents labeled at the terminal end of the polypeptide chain or side chain of lysine (7). According to the analysis of high-resolution mass spectrometry, ITRAQ can compare eight samples 
simultaneously. Although it has disadvantages, including interference by coeluting peptides with close $\mathrm{m} / \mathrm{z}$, it is accurate in quantitative analysis, possesses a low error rate, has high efficiency and has a wide range of applications, among other advantages (8). In recent years, the technique has been commonly used in high-throughput screening technology in quantitative proteomics.

In the present study, ITRAQ technology combined with mass spectrometry was used to investigate the MI model in beagle dogs. The whole workflow of the study is shown in Fig. 1. The serum protein expression was assessed prior to MI model establishment ( $0 \mathrm{~h})$, and after 1,2 and $3 \mathrm{~h}$. The differentially expressed proteins (DEPs) were annotated, and the protein-protein interaction (PPI) network was analyzed bioinformatically. Western blot analysis was used to evaluate the results obtained from ITRAQ, which may provide an in-depth understanding of the pathophysiological process of MI, thereby proposing a novel direction for the diagnosis of early MI.

\section{Materials and methods}

Beagle dogs and MI model. A total of 30 healthy beagle dogs (9 months old, male:female ratio, 1:1) weighing 10-12 kg were purchased from Shanghai Xingang Laboratory, Animal Farm (Shanghai, China). Ethics approval was obtained prior to the start of the study. All animal procedures were performed in accordance with the Animal Care Committee of Zhejiang Hospital (Hangzhou, China). Beagle dogs were housed in an environment of $16-28^{\circ} \mathrm{C}$, relative humidity of $45-60 \%$ with a 12 -h light/dark cycle, fed rice every $12 \mathrm{~h}$ ( $2 \%$ body weight each time) and were given free access to water. All dogs were fasted for $12 \mathrm{~h}$ and water-deprived for $4 \mathrm{~h}$ prior to surgery. For anesthesia, $3 \%$ pentobarbital sodium $(30 \mathrm{mg} / \mathrm{kg}$ ) was injected via the left venae tibiales anteriores. When the dogs were asleep, touching the eyelashes and the cornea without reaction confirmed that the anesthesia was successful. The right femoral arteries of the beagles were punctured for coronary angiography (Fig. 2A). First, the balloons were inserted to the second diagonal branches, and then expanded every $30 \mathrm{sec}$ for ischemic preconditioning (Fig. 2B). Subsequently, the balloons were withdrawn and microcatheters were inserted to the second diagonal branches. An equivalent of $2 \mathrm{ml}$ of polyethylene microsphere suspension was rapidly injected into the target vessel via microcatheters, followed by the injection of $2 \mathrm{ml}$ thrombin powder formulation. After 5-10 min, the coronary angiography was repeated to confirm the interruption of blood flow. Finally, the microcatheters were withdrawn from the target vessel and the surgery ended. The heart vessel angiograms were collected at 2, 3 and $6 \mathrm{~h}$, and 3 days after MI (Fig. 2C-F). In cases in which a dog died, they were immediately dissected to determine the cause of death. Following the injection of $3 \%$ pentobarbital sodium $(30 \mathrm{mg} / \mathrm{kg})$ through the left venae tibiales anteriores for anesthesia, all surviving dogs were administered with $10 \% \mathrm{KCL}(80 \mathrm{mg} / \mathrm{kg})$ solution through the left venae tibiales anteriores for sacrifice. The disappearance of blood pressure and cardiac arrest were used for the confirmation of animal death.

Serumprotein sample preparation. A 20-ml volume of peripheral venous blood was withdrawn into coagulation-promoting vacuum tubes (Zhejiang Hospital) prior to MI model establishment $(0 \mathrm{~h})$ and at 1,2 and $3 \mathrm{~h}$ thereafter. The tubes were then rested for $30 \mathrm{~min}$, following which serum was obtained by centrifugation $\left(15,00 \mathrm{~g}, 10 \mathrm{~min}, 4^{\circ} \mathrm{C}\right)$. The serum protein solutions were concentrated by $10 \mathrm{kDa}$ Vivaspin $=500$ (Sartorius AG, Göttingen, Germany). The protein concentration was measured using the BCA Assay kit (Sigma; Merck KGaA, Darmstadt, Germany). The compressed serum samples were stored at $-80^{\circ} \mathrm{C}$ until further analysis (9).

ITRAQ sample preparation. The ITRAQ reagent-8plex multiplex kit was purchased from AB SCIEX (Washington, DC, USA). An equivalent of $30 \mu \mathrm{l}(100 \mathrm{mM})$ protein sample was mixed with dithiothreitol, and was denatured in a boiling water bath for $5 \mathrm{~min}$ and cooled to room temperature. The clarified supernatants were then transferred to $30 \mathrm{kDa}$ ultrafiltration units. The filters were rinsed three times with $8 \mathrm{M}$ urea followed by incubation with iodoacetamide for $30 \mathrm{~min}$ at room temperature. Subsequently, three additional washes with $8 \mathrm{M}$ urea and three washes with dissolution buffer (AB SCIEX) were performed.

All samples were digested with $40 \mu$ l trypsin ( $4 \mu \mathrm{g}$ trypsin in $40 \mu \mathrm{l}$ dissolution buffer) at $37^{\circ} \mathrm{C}$ overnight. Subsequently, the peptides were desalted with the C18 Cartridge (cat. no. 66872-U; Sigma; Merck KGaA), lyophilized, and resolubilized in $40 \mu \mathrm{l}$ dissolution buffer (10). The acquired peptides were then labeled with the ITRAQ reagents as follows: $0 \mathrm{~h}$ group was labeled with ITRAQ 113, $1 \mathrm{~h}$ group was labeled with ITRAQ 114, $2 \mathrm{~h}$ group was labeled with ITRAQ 115, and $3 \mathrm{~h}$ group was labeled with ITRAQ 116. All peptides were mixed for the subsequent step.

Strong cation exchange (SCX) separation. The peptide mixture was diluted with the SCX buffer A $\left[10 \mathrm{mM} \mathrm{KH}_{2} \mathrm{PO}_{4}\right.$ in $25 \%$ acetonitrile (ACN), pH 3.0]. Fractionation was performed using the AKTA Purifier 100 (GE Healthcare Life Sciences, Little Chalfont, UK) equipped with a polysulfoethyl column (4.6x100 mm, $5 \mu \mathrm{m}, 200$ A, PolyLC, Inc., Columbia, MD, USA). The flow rate was $1 \mathrm{ml} / \mathrm{min}$. The gradient of the liquid phase was as follows: 0-22 min linear binary gradient of SCX buffer $\mathrm{B}$ $\left(10 \mathrm{mM} \mathrm{KH}_{2} \mathrm{PO}_{4}\right.$ and $500 \mathrm{mM} \mathrm{KCL}$ in $25 \% \mathrm{ACN}, \mathrm{pH} 3.0$ ), $0-8 \%$; 22-47 min the linear binary gradient of SCX buffer B, $8-52 \%$; 47-50 min of linear binary gradient of SCX buffer B, $52-100 \%$; 50-58 min of linear binary gradient of SCX buffer B at $100 \%$; 58-60 min of linear binary gradient of SCX buffer B reset to $0 \%$. The fractions were combined into 20 groups.

Liquid chromatography-mass spectrometry (LC-MS) analysis. All sample fractions were examined by high-performance liquid chromatography using an Easy nLC system (Thermo Fisher Scientific, Inc., Waltham, MA, USA). C18-A2 EASY-columns $(10 \mathrm{~cm}$, ID75 $\mu \mathrm{m}, 3 \mu \mathrm{m}$; Thermo Fisher Scientific, Inc.) were used to separate the peptides. First, all fractions were concentrated using a vacuum centrifuge concentrator (Eppendorf Concentrator Plus, Eppendorf, Hamburg, Germany) and solubilized buffer A ( $0.1 \%$ formic acid in water). The desalted samples were loaded onto a nanoViper C18 column (100 $\mu \mathrm{m} \times 2 \mathrm{~cm}, 3 \mu \mathrm{m}, 100 \mathrm{~A})$ by autosamplers (both Thermo Fisher Scientific, Inc.) and fractionated in an EASY-column at a flow rate of $300 \mathrm{nl} / \mathrm{min}$. 


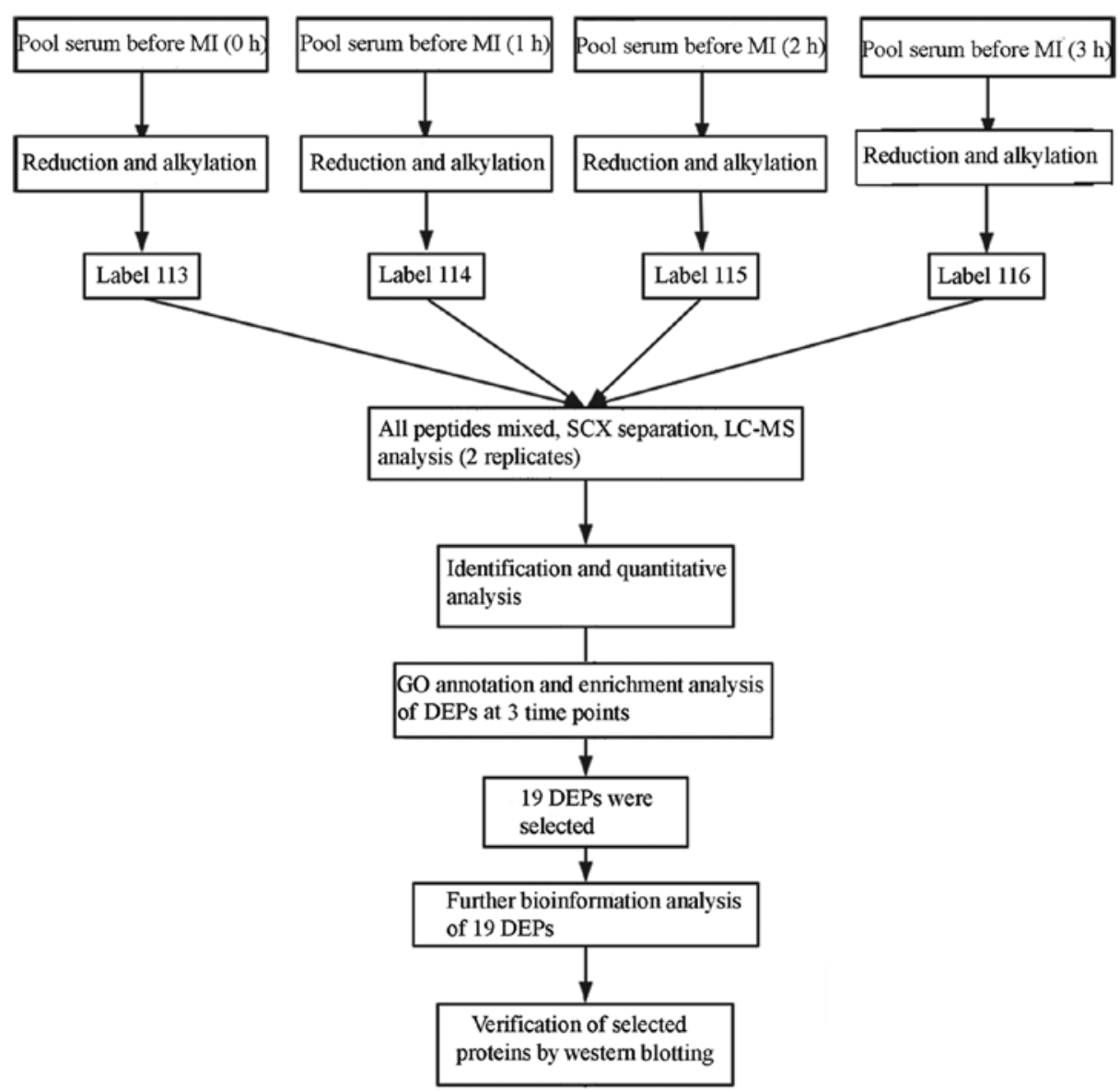

Figure 1. Entire workflow of proteomics using ITRAQ combined LC-MS technology. Serum protein pre-MI $(0 \mathrm{~h})$ was regarded as the control group, the obtained differential expressed proteins were subjected to further bioinformatics analysis. Selected proteins were verified by western blot analysis. MI, myocardial infarction; SCE, strong cation exchange; LC-MS, liquid chromatography-mass spectrometry; GO, Gene Ontology; ITRAQ, isobaric tags for relative and absolute quantitation; DEP, differentially expressed protein.
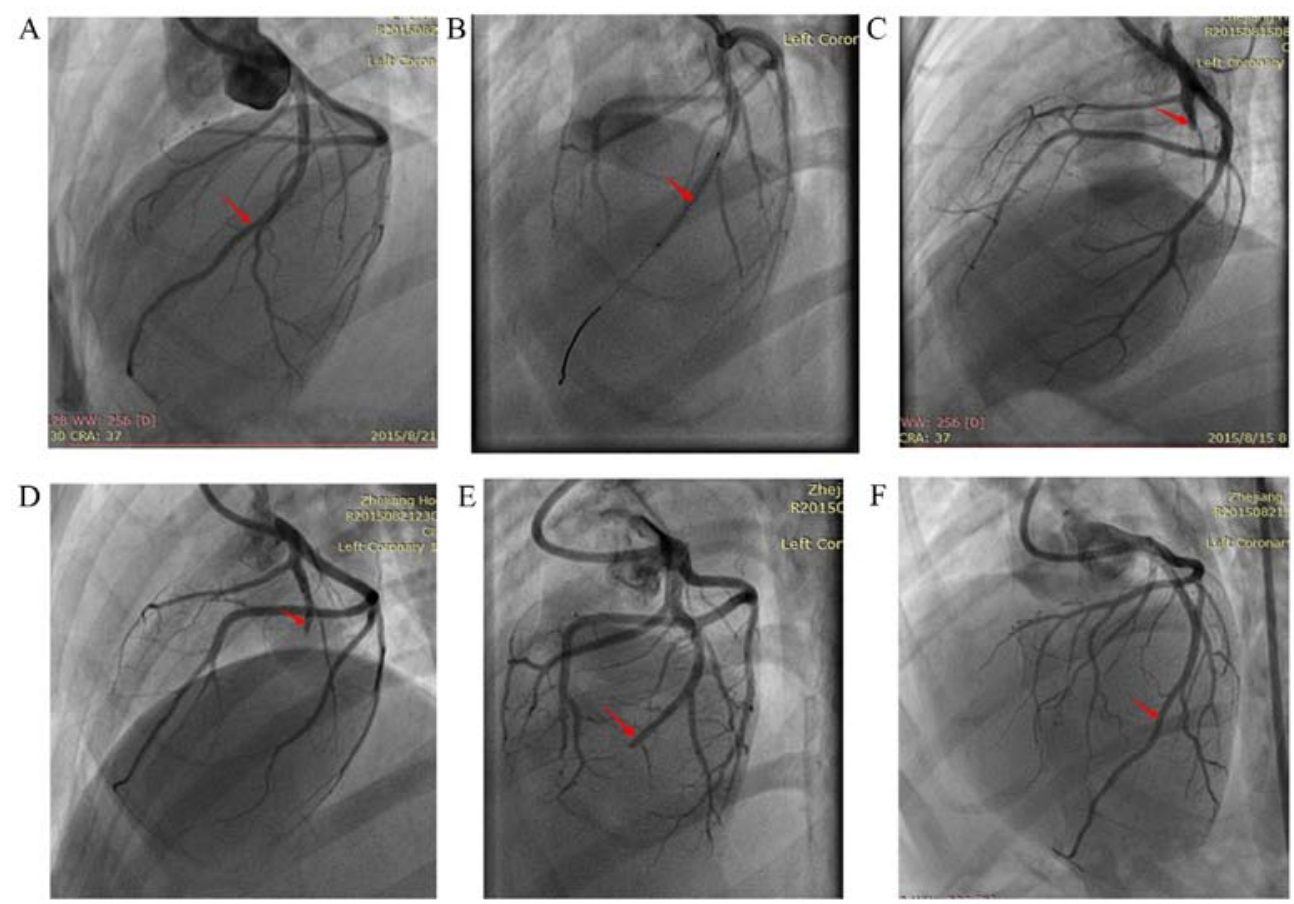

Figure 2. Coronary angiography images of beagle dogs. (A) Left coronary angiography prior to intervention occlusion surgery ( $0 \mathrm{~h})$, the red arrows refer to the LAD. (B) Ischemia preconditioning by balloon dilation. (C) Left coronary angiography $2 \mathrm{~h}$ post-LAD embolism. (D) Left coronary angiography $3 \mathrm{~h}$ post-LAD embolism (E) Left coronary angiography $6 \mathrm{~h}$ post-LAD embolism, the second diagonal branch reappeared. (F) Left coronary angiography 3 days post-LAD embolism, the blood-flow of the LAD had returned to normal. LAD, left anterior descending artery. 
The mobile phases consisted of $0.1 \%$ formic acid in water (A) and $0.1 \%$ formic acid, $84 \%$ ACN in water (B) operated at $300 \mathrm{nl} / \mathrm{min}$ constant flow with a gradient profile over the course of $60 \mathrm{~min}$, as follows (min:\%B): 0:5, 50:35, 55:100, and 60:100.

Subsequently, the fractions were analyzed by Q-Exactive (Thermo Fisher Scientific, Inc.), and the key parameters of the first-class MS were as follows: Cation scanning; scan range, $300-1,800 \mathrm{~m} / \mathrm{z}$; resolution, 70,000 at $200 \mathrm{~m} / \mathrm{z}$; AGC target, 3e6; first class maximum IT, $10 \mathrm{msec}$; one scan range; dynamic exclusion, $40.0 \mathrm{sec}$.

The mass-charge ratio of the polypeptide and polypeptide fragments was as follows: Mode: MS2 scan; MS2 activation type: HCD; isolation window: $2 \mathrm{~m} / \mathrm{z}$.

The key parameters of MS/MS were as follows: Resolution, 17,500 at $200 \mathrm{~m} / \mathrm{z}$; one microscan; second class MS resolution, $60 \mathrm{msec}$; normalized collision energy, $30 \mathrm{eV}$.

Analysis of DEPs. The original data form was prepared in RAW. Mascot 2.2 (Matrix Science, Ltd., London, UK) and Proteome Discoverer 1.4 software (Thermo Fisher Scientific, Inc.) were used for peptide and protein identification, and RAW files were converted to Mascot Generic Format (MGF) files with preselected iTRAQ reporter ions. The MGF files were searched against the Uniprot_Canislupusfamiliaris 29014_20160822.fasta database (http//:www.uniprot.org) and the parameters were as follows: Enzyme, trypsin; maximum missed cleavages, two; fixed modifications, carbamidomethyl (C-terminal), ITRAQ 8 plex (N-term), ITRAQ 8 plex (K); variable modification, oxidation (M), ITRAQ 8 plex (Y); peptide mass tolerance, $\pm 20 \mathrm{ppm}$; fragment mass tolerance, $0.1 \mathrm{Da}$; database pattern, decoy; peptide false discovery rate (FDR), $\leq 0.01$.

Only proteins identified with confidence interval values $>95 \%, \mathrm{P}<0.05$ and expression ratio $>1.2$ or $<0.83$ were considered as DEPs.

Bioinformatics analysis. Functional annotation and enrichment analysis were performed using Gene Ontology (GO) software online (http://www.geneontology.org). The significance of GO terms was evaluated according to Fisher's exact test, and the common GO terms satisfied $\mathrm{P}<0.05$ in the three comparison groups. All proteins in these common GO terms were defined as critical and subjected to further analysis. A Venn diagram was produced using Microsoft Office Excel 2007 (Microsoft Corporation, Redmond, WA, USA). A heatmap was produced using Heatmap Illustrator 1.0.3.3 (http://hemi.biocuckoo.org/). The PPI network including the key proteins was constructed using the online STRING database (http://string-db.org/). GO and Kyoto Encyclopedia of Genes and Genomes (KEGG) enrichment analyses were also performed using STRING software, with those categories with FDR $<0.05$ listed.

Western blot analysis. In order to verify the ITRAQ results, three DEPs, fibrinogen $\gamma$ chain (FGG), ATP synthase F1 subunit $\beta$ (ATP5B) and integrator complex subunit 4 (INTS4), were selected for further analysis by western blotting. Equivalent quantities of serum protein sample $(3 \mu \mathrm{l})$ were initially electrophoresed on 5\% stacking SDS-PAGE for 40 min under $60 \mathrm{~V}$, then electrophoresed on $10 \%$ separating
SDS-PAGE for 80 min under $80 \mathrm{~V}$ (cat. no. 161-0156; Bio-Rad Laboratories, Inc., Hercules, CA, USA) and transferred onto polyvinylidene fluoride membranes for 80 min under $80 \mathrm{~V}$ (cat. no. IPVH00010; EMD Millipore, Billerica, MA, USA). Subsequently, the membranes were blocked in 5\% skim milk Tris-buffered saline containing Tween-20 (TBST; Thermo Fisher Scientific, Inc.) at room temperature for $1 \mathrm{~h}$. The membranes were then washed with TBST three times and probed with the following primary antibodies at $4^{\circ} \mathrm{C}$ overnight: Rabbit anti-transferrin receptor 1 (TFRC) 1 antibody, (1:1,000; cat. no. LS-C186620-100; LifeSpan BioSciences, Inc., Seattle, WA, USA), rabbit anti-INTS4 antibody, (1:1,000; cat. no.ab182329), rabbit anti-FGG antibody (1:200; cat. no. ab62527), rabbit anti-ATP5B antibody (1:1,000; cat. no. ab128743; all Abcam, Cambridge, MA, USA). This was followed by incubation with horseradish peroxidase-labeled secondary antibodies (goat anti-rabbit IgG secondary antibodies; 1:5,000; cat. no. 31210; Thermo Fisher Scientific, Inc.) at room temperature for $1 \mathrm{~h}$. Finally, the membranes were washed five times with TBST and visualized using an ECL DualVue WB Marker (cat. no. RPN810; GE Healthcare Life Sciences). The densities of the immunoreactive bands were quantified on an X-ray film (Huadong Medicine Co., Ltd., Hangzhou, China) (11).

Statistics analysis. The ITRAQ data were analyzed in Perseus software (http://www.coxdocs.org/doku.php?id=perseus:sta rt\#cite) (12), other data were analyzed in SPSS software for Windows, version 19.0 (IBM Corp., Armonk, NY, USA). One way analysis of variance (ANOVA) was used to evaluate the statistical significance among multiple groups during the validation step; the differences between different time points were analyzed using the Least Significant Difference test. Prior to one way ANOVA, the normality was confirmed using the Shapiro-Wilk test $(\mathrm{P}>0.05)$, and the homogeneity of variances using the $\mathrm{F}$ test $(\mathrm{P}>0.05)$. $\mathrm{P}<0.05$ was considered to indicate a statistically significant difference.

\section{Results}

Coronary angiography images of beagle dogs. All beagle dogs underwent left coronary angiography successfully. Four beagle dogs presented with ventricular fibrillation during surgery, three died, and one survived following defibrillation and anti-arrhythmia therapy. Seven beagle dogs died within $24 \mathrm{~h}$ after surgery and a total of nine died within the 2 weeks following surgery. Following postoperative death, the beagle dogs were dissected, and bilateral lung congestion was detected. Heart failure was considered to be the major factor associated with the mortality of these dogs (image not shown).

Coronary angiography at $2 \mathrm{~h}$ post-embolization suggested full closure of the proximal left coronary artery (Fig. 2C). At $6 \mathrm{~h}$ post-embolization, coronary angiography suggested that the blood flow in the proximal left coronary artery was restored (Fig. 2E). At 3 days post-embolization, coronary angiography suggested recanalization of the left anterior descending (LAD) artery (Fig. 2F).

DEPs at different time points. In order to minimize the experimental error generated during the experiment, the LC-MS 
analysis was repeated twice. The results of the first analysis revealed 562 proteins, whereas 554 proteins were detected in the second. Among these, 462 common proteins were identified in the two identifications. In addition, the mass accuracy of all identified peptides was checked, and it was found that only $\sim 1 \%(42 / 4,542)$ of the peptides had a molecular weight deviation $>10 \mathrm{ppm}$, which indicates a high mass accuracy in the study. Proteins with confidence interval values $>95 \%$ and $\mathrm{P}<0.05$ were identified and considered as DEPs (Table SI). The number of DEPs was 51 at $1 \mathrm{~h}$ post-MI compared with that at $0 \mathrm{~h}$, including 28 upregulated and 23 downregulated proteins. The number of DEPs was 54 at $2 \mathrm{~h}$ post-MI compared with that at $0 \mathrm{~h}$, including 28 upregulated and 26 downregulated proteins. The number of DEPs was 43 at $3 \mathrm{~h}$ post-MI compared with that at $0 \mathrm{~h}$, including 24 upregulated and 19 downregulated proteins. A Venn diagram was produced to clarify the association of DEPs among the three time points (Fig. 3).

Biological function analysis of DEPs. The GO annotation analysis determined the biological functions of the DEPs pre- and post-MI based on three aspects: Biological process, molecular function and cellular component.

In the $1 \mathrm{~h} / 0 \mathrm{~h}$ comparison (Table SII), 39 proteins were found to be related to biological process; these were primarily involved in a single-organism process (28 proteins, $72 \%$ ), cellular process (26 proteins, 67\%), metabolic process (19 proteins, 49\%) and biological regulation (13 proteins, $33 \%)$. The 43 proteins found to be related to molecular function were mainly involved in binding (31 proteins, $72 \%$ ) and catalytic activity (12 proteins, $28 \%$ ), and the 41 proteins related to cellular component were mainly distributed in the cell (30 proteins, $72 \%$ ) and organelle (20 proteins, $47 \%$ ).

In the $2 \mathrm{~h} / 0 \mathrm{~h}$ comparison (Table SIII), 43 proteins were related to the biological process; these were mainly involved in the single-organism process (32 proteins, $74 \%$ ), cellular process (30 proteins, $74 \%$ ), biological regulation (20 proteins, $47 \%$ ) and metabolic process (17 proteins, $40 \%$ ). The 46 proteins related to molecular function were primarily involved in binding (37 proteins, $80 \%$ ) and catalytic activity (15 proteins, $46 \%$ ), similar to the $1 \mathrm{~h} / 0 \mathrm{~h}$ comparison. The 43 proteins related to the cellular component were distributed in the cell (30 proteins, $70 \%$ ) and organelle (21 proteins, $49 \%$ ). In addition, the cell membranes also had a specific number of DEPs (13 proteins, $30 \%$ ).

In the $3 \mathrm{~h} / 0 \mathrm{~h}$ comparison (Table SIV), 34 proteins were related to the biological process, and primarily involved in the metabolic process (20 proteins, 59\%), cellular process (20 proteins, 59\%), single-organism process (18 proteins, $53 \%$ ) and biological regulation (12 proteins, 35\%). A total of 36 proteins were related to molecular function, and similar to the $1 \mathrm{~h} / 0 \mathrm{~h}$ comparison, were primarily involved in binding (24 proteins, 67\%), catalytic activity (16 proteins, 44\%) and binding to organic cyclic compounds (12 proteins, 34\%). The 32 proteins related to the cellular component were distributed in the cell (20 proteins, 63\%) and organelle (14 proteins, $44 \%$ ). In addition, similar to the $2 \mathrm{~h} / 0 \mathrm{~h}$ comparison, the cell membranes had a specific number of DEPs (seven proteins, $22 \%)$.

In order to compare the importance of different GO terms pre- and post-MI, GO enrichment analysis was performed

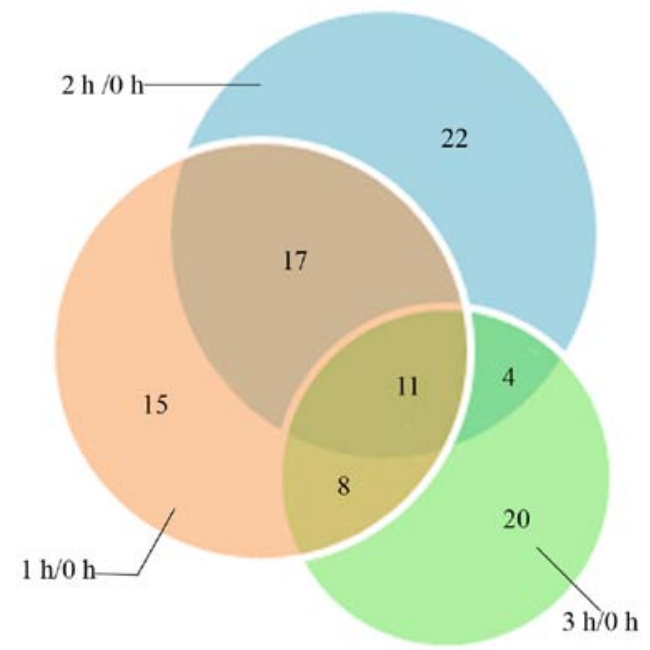

Figure 3. Venn diagram of all DEPs at the three time points. A Venn diagram of all DEPs at the three time points is presented. There were 51, 54 and 43 DEPs at $1 \mathrm{~h} / 0 \mathrm{~h}, 2 \mathrm{~h} / 0 \mathrm{~h}$ and $3 \mathrm{~h} / 0 \mathrm{~h}$, respectively. In addition, 17 DEPs were common to the $1 \mathrm{~h}$ and $2 \mathrm{~h}$ time points; eight DEPs were common to the $1 \mathrm{~h}$ and $3 \mathrm{~h}$ time points; four DEPs were common in the $2 \mathrm{~h}$ and $3 \mathrm{~h}$ time points; 11 DEPs were common to the $1 \mathrm{~h}, 2$ and $3 \mathrm{~h}$ time points. DEPs, differentially expressed proteins.

(Table SV). According to the enrichment analysis, a total of 10 common GO terms were found in the three comparisons as follows: Oxygen transport, gas transport, hemoglobin complex, oxygen binding, heme binding, tetrapyrrole binding, protein complex, iron ion binding, cytosolic part, and macromolecular. A total of 19 DEPs were selected from the $10 \mathrm{GO}$ terms and considered to be key proteins (Table I). Hierarchical clustering analysis was used to analyze the expression of these 19 key proteins at three different time points. The results are shown in a heatmap (Fig. 4A). The data used for the heatmap was the average of two repetitions. Each line in the heatmap represents a protein with the mean upregulation (red) or downregulation (green) in expression within the three time points, no change in expression is indicated in white.

The hierarchical clustering analysis roughly divided the 19 proteins into four main patterns (Fig. 4B). Proteins that increased between 0 and $1 \mathrm{~h}$ post-MI were in pattern 1 , including F1PTY1 [keratin (KRT)1], E2REU6 (KRT18), E2R489 (KRT84) and J9NWS3 (KRT9). KRT is the main protein that constitutes the epidermis and fur hair follicles (13); however, there appears to be no evidence on the association between keratin and AMI in the existing literature. In pattern 2, proteins were significantly increased within $2 \mathrm{~h}$ post-AMI, but showed a downward trend between 2 and $3 \mathrm{~h}$, including F1PBL4 [FGA], F1PGS2 (FGB) and F1P8G0 (FGG). FG is involved in the coagulation and platelet activation pathway, and is important in the thrombus formation. Several studies have reported on the association between FG and AMI $(14,15)$. In pattern 3, proteins decreased significantly in the third hour, including E2RL75 (INTS4), F1PH83 [component of oligomeric golgi complex 7 (COG7)], Q0QEN2 (ATP5B), C4MW55 [cytochrome $c$ oxidase subunit 2 (COX2)] and F6X5M3 [clathrin light chain B (CLTB)]. A number of the proteins, including ATP5B and COX2, are involved in the composition of the electron transport chain (16). COG-7, a subunit of the conserved oligomeric Golgi complex, is involved in the further 
Table I. Basic information of differentially expressed proteins.

\begin{tabular}{|c|c|c|c|c|c|}
\hline Accession no. & Gene symbol & $1 \mathrm{~h} / 0 \mathrm{~h}$ & $2 \mathrm{~h} / 0 \mathrm{~h}$ & $3 \mathrm{~h} / 0 \mathrm{~h}$ & $\begin{array}{c}\text { Significant } \\
\text { time point } \\
(\mathrm{P}<0.05)\end{array}$ \\
\hline J9JHF7 & $\begin{array}{c}\text { LOC100855540 } \\
\text { (ENSCAFG00000032615) }\end{array}$ & 1.6132 & 2.33704 & 2.3493 & $1 \mathrm{~h}, 2 \mathrm{~h}, 3 \mathrm{~h}$ \\
\hline F1PYZ1 & LOC485255(HBD) & 2.0078 & 1.14914 & 2.6074 & $1 \mathrm{~h}, 2 \mathrm{~h}$ \\
\hline J9JHZ3 & LOC476825 & 1.4238 & 1.51391 & 1.45468 & $1 \mathrm{~h}, 2 \mathrm{~h}$ \\
\hline F1P8V6 & $\mathrm{Mb}$ & 0.8774 & 2.54093 & 1.8720 & $2 \mathrm{~h}, 3 \mathrm{~h}$ \\
\hline P00011 & CYCS & 1.0814 & 1.05109 & 1.5515 & $3 \mathrm{~h}$ \\
\hline J9NU17 & MYO1A & 2.5885 & 3.6345 & 2.1319 & $1 \mathrm{~h}, 2 \mathrm{~h}, 3 \mathrm{~h}$ \\
\hline C4MW55 & COX2 & 1.4277 & 0.84775 & 0.5386 & $1 \mathrm{~h}, 3 \mathrm{~h}$ \\
\hline F1PTY1 & KRT1 & 1.4629 & 0.90146 & 1.0768 & $1 \mathrm{~h}$ \\
\hline E2RL75 & INTS4 & 1.3284 & 1.2349 & 0.5016 & $1 \mathrm{~h}, 3 \mathrm{~h}$ \\
\hline E2REU6 & KRT18 & 1.6622 & 1.06858 & 1.2304 & $1 \mathrm{~h}$ \\
\hline F1Q0N9 & KRT19 & 1.8121 & 1.13388 & 2.9467 & $1 \mathrm{~h}, 3 \mathrm{~h}$ \\
\hline F1PH83 & COG7 & 0.7355 & 0.91037 & 0.6618 & $1 \mathrm{~h}$ \\
\hline F6X5M3 & CLTB & 1.3703 & 1.1251 & 0.8135 & $1 \mathrm{~h}$ \\
\hline E2R489 & KRT84 & 1.4417 & 0.95866 & 1.1761 & $1 \mathrm{~h}$ \\
\hline J9NWS3 & KRT9 & 2.4965 & 1.04879 & 1.0036 & $1 \mathrm{~h}$ \\
\hline Q0QEN2 & ATP5B & 0.5946 & 0.72595 & 0.4211 & $1 \mathrm{~h}, 2 \mathrm{~h}, 3 \mathrm{~h}$ \\
\hline F1P8G0 & FGG & 2.0490 & 2.24377 & 1.3447 & $1 \mathrm{~h}, 2 \mathrm{~h}$ \\
\hline F1PBL4 & FGA & 2.6063 & 2.67755 & 1.3737 & $1 \mathrm{~h}, 2 \mathrm{~h}$ \\
\hline F1PGS2 & FGB & 2.4915 & 2.55351 & 1.3501 & $1 \mathrm{~h}, 2 \mathrm{~h}$ \\
\hline
\end{tabular}

processing of intracellular synthetic proteins (17), whereas CLTB is important in the transport of small molecules, including neurotransmitters and membrane proteins, in the human body (18). The decline in the expression of these proteins indicates that disorder of energy metabolism may be an important factor in the early stages of AMI. In pattern 4, proteins increased significantly in the third hour, including F1PYZ1 (LOC485255), J9JHZ3 (LOC476825), F1P8V6 [myoglobin (Mb)], J9JHF7 (LOC100855540), P00011 [cytochrome $c$ (CYCS)], F1Q0N9 (KRT19) and J9NU17 [myosin IA (MYO1A)]. LOC100855540, LOC4852 55 and LOC476825 are corresponding gene symbols of hemoglobin subunit $\alpha$-like, hemoglobin subunit $\varepsilon-2$ and hemoglobin subunit $\beta$ of beagle dogs. They are considered to serve important roles in the utilization of blood oxygen, however, no relevant reports on these proteins in AMI are present in the literature. MYO1A is involved in myokinesis (19), whereas CYCS is the electron transport body in the process of biological oxidation (20). Although the proteins in this pattern are involved in different biological processes, no common features of the proteins in pattern 4 have been identified at present.

Further bioinformatics analyses of 19 selected DEPs. To further understand the potential mechanism underlying these DEPs, a PPI regulatory network was analyzed using STRING software. The PPI evidence-view was used, in which the line color indicates the type of interaction evidence. The network contained 19 nodes and 15 edges with an average node degree of 1.58 and local clustering coefficient of 0.558 ; the expected number of edges was one (Fig. 5). The PPI enrichment p-value was $4.11 \mathrm{E}-13(<0.01)$, this means that there are more interac- tions amongst the proteins than expected for a random set of proteins of a similar size, drawn from the genome. Such an enrichment p-value indicates that the proteins are at least partially biologically connected, as a group. The PPI network revealed that the interactions between the 19 DEPs were interconnected and effectuated as a group.

The functional enrichment analysis revealed that the 19 selected DEPs were involved in several significant GO terms (Fig. 6). In the biological process category, there were six GO terms, including blood coagulation (GO:0007596, three proteins), single-organism process (GO:0044699, seven proteins), wound healing (GO:0042060, three proteins), electron transport chain (GO:0022900, two proteins), single-multicellular organism process (GO:0044707, four proteins) and innate immune response (GO:0045087, two proteins). In the molecular function category, four GO terms included molecule function (GO:0003674, six proteins), structural molecule activity (GO:0005198, three proteins), electron carrier activity (GO:0009055, two proteins) and heme binding (GO:0020037, two proteins). The cellular component category comprised 15 GO terms that mainly included intermediate filament (GO:0005882, two proteins), protein complex (GO:0043234, four proteins), intermediate filament cytoskeleton (GO:0045111, two proteins), intracellular organelle part (GO:0044446, four proteins), respiratory chain (GO:0070469, two proteins), membrane (GO:0016020, four proteins), mitochondrial envelope (GO:0005740, two proteins). These molecular functions were closely related to electron transport and energy metabolism, which suggested that the energy metabolism disorder of cardiomyocytes is the initial pathophysiological feature of AMI. In addition, certain 

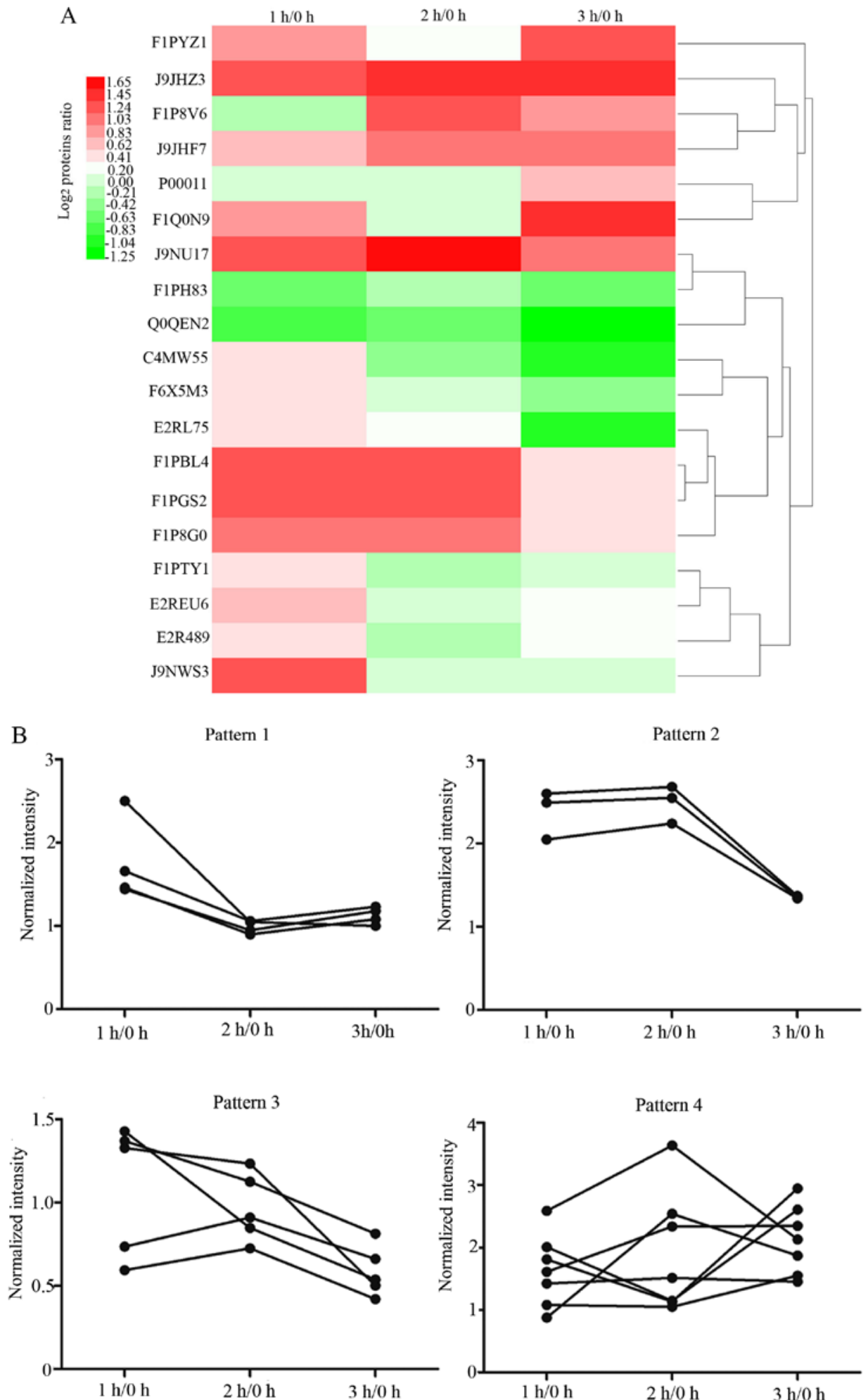

Figure 4. Heatmap and cluster analysis of 19 DEPs at 1, 2 and $3 \mathrm{~h}$ post-MI, vs. pre-MI $(0 \mathrm{~h})$. (A) Each line in the heatmap represents a protein with upregulated (red) or downregulated (green) expression at three time points post-MI, vs. pre-MI, whereas white represents no change in expression. A complete list of the 19 selected DEPs is present in Table I. (B) All 19 proteins were divided into four groups according to different expression patterns (patterns 1-4). MI, myocardial infarction; DEPs, differentially expressed proteins.

proteins were distributed in the intermediate filament, which serves a major role in the transfer of intracellular substances and maintains the stability of cell morphology.

KEGG enrichment analysis was performed using the STRING database (Fig. 7). A total of seven pathways were considered significant. Biological functions related to these proteins were obtained from the KEGG enrichment analysis in Fig. 7. The complement and coagulation cascades pathway consisted of three proteins, FGA, FGB and FGG, and the composition of the platelet activation pathway was consistent with the complement and coagulation cascades pathway. These pathways suggested that platelet activation and coagu- 


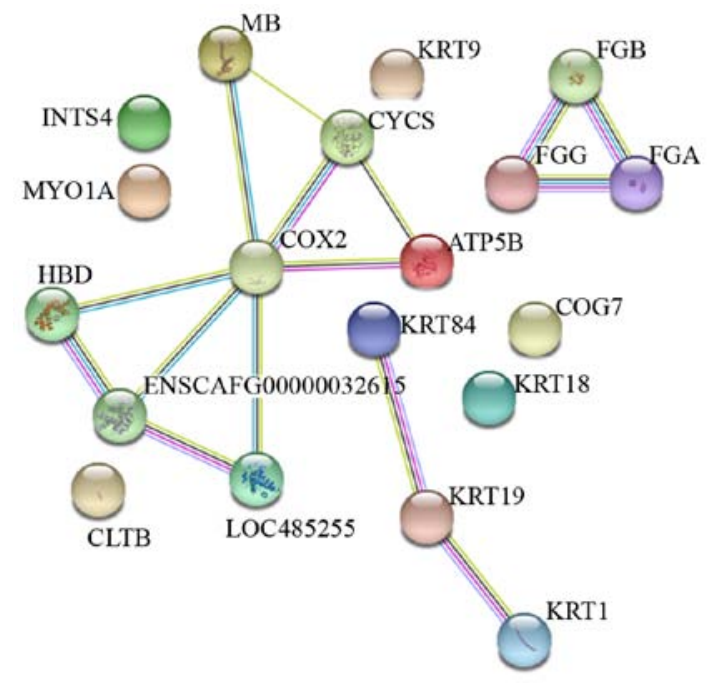

Figure 5. PPI regulatory network of DEPs. All DEPs were combined together to form a complex interaction network using STRING software. The network contained 19 nodes and 15 edges. Average node degree: 1.58; local clustering coefficient: 0.558; expected number of edges: one. The PPI enrichment P-value was 4.11e-13. HBD represents LOC476825, ENSCAFG00000032615 represents LOC1008-55540. PPI, protein-protein interaction; DEPs, differentially expressed proteins.

lation disorders may be triggers of AMI, and related content has been confirmed in several studies $(21,22)$. Huntington's disease, Parkinson's disease and Alzheimer's disease are common chronic progressive neurodegenerative disorders, however, there are few reports detailing the association between these three diseases and AMI. ATP5B, CYCS and COX2 are involved in the formation of these pathways; in addition, these proteins are involved in the electron transport chain (23-25). In the process of oxidative stress, the production of oxygen free radicals causes corresponding changes in the expression of these proteins, eventually affecting the metabolism of energy (26). African trypanosomiasis and malaria are parasitic diseases, and reports on the associations between the two disorders and MI are also lacking. The proteins that make up these two pathways were found to be identical (HBD and ENSCAFG-00000032615); it was hypothesized that this may be associated with the destruction of red blood cells caused by oxygen free radicals. Unfortunately, there is currently no relevant literature to confirm this. The link between these pathways and AMI remains to be fully elucidated and necessitates further investigation.

Validation analysis by western blot analysis. The validation of the candidate biomarkers was critical. As mentioned above, according to the heatmap and PPI network, all proteins were roughly divided into four groups. The first group included FGA, FGB and FGG, which are monomers that make up fibrinogen. In the ITRAQ results, the expression of the three proteins within $3 \mathrm{~h}$ was similar (Table I). This appears to illustrate the similarity of the three proteins, and FGG was selected for further verification. The second group included ATP5B, COX2 and CYCS, which are mainly involved in the electron transport chain and energy generation. Although COX2 was at the core of the cluster, it was not possible to obtain the corresponding beagles' primary antibody.
According the results of ITRAQ [1 h/0 h: 0.59; $2 \mathrm{~h} / 0 \mathrm{~h}: 0.73$, $3 \mathrm{~h} / 0 \mathrm{~h}$ : 0.42] (Table I), the expression of ATP5B decreased at all three time points. It was anticipated that the protein used for verification is ideally detected sooner (within $1 \mathrm{~h}$ ) and stabilizes for a period of time (at least $3 \mathrm{~h}$ ). ATP5B fully met the requirements and was selected for further verification. The third group included KRT1, KRT19 and KRT84; there are no data suggesting a link between KRT1, KRT19, KRT84 and $\mathrm{MI}$, therefore, none of these proteins were selected for further verification. There were also other proteins that are not involved in the composition of the network. These scattered proteins were classified into one group and INTS4 was selected for further verification, as the corresponding beagle primary antibody was obtained and the expression of INTS4 altered significantly within $1 \mathrm{~h}$. Based on the above results, INTS4, FGG and ATP5B were selected for further validation according to western blot analysis. These proteins were selected as the association between them and MI had not been established so far. In addition, the corresponding beagle antibody was available to purchase. They cover a considerable proportion of the important biological processes that the 19 key proteins involved in. In addition, the expression of TFRC 1 was relatively stable according the ITRAQ results, as the internal reference of the experiment. Serum samples from 10 beagle dogs were collected and interesting results were obtained from the images. As shown in Fig. 8, with the expression of TFRC 1 at $0 \mathrm{~h}$ as ' 1 ', the expression of TFRC did not alter significantly at the three points $[1 \mathrm{~h} / 0 \mathrm{~h}$ : $0.95 \pm 0.12(\mathrm{P}>0.05) ; 2 \mathrm{~h} / 0 \mathrm{~h}: 1.03 \pm 0.10(\mathrm{P}>0.05), 3 \mathrm{~h} / 0 \mathrm{~h}$ : $1.05 \pm 0.10(\mathrm{P}>0.05)$, Fig. $8 \mathrm{~A}$ and $\mathrm{B}]$. The results of the western blotting were basically consistent with the ITRAQ results [1 h/0 h: 1.11 \pm 0.15 ( $\mathrm{P}>0.05) ; 2 \mathrm{~h} / 0 \mathrm{~h}: 1.12 \pm 0.11(\mathrm{P}>0.05)$, $3 \mathrm{~h} / 0$ h: $1.10 \pm 0.12(\mathrm{P}>0.05)$; Table SI]. There were no statistically significant differences between the $2 \mathrm{~h} / 0 \mathrm{~h}$ and $1 \mathrm{~h} / 0 \mathrm{~h}$ groups, $2 \mathrm{~h} / 0 \mathrm{~h}$ and $3 \mathrm{~h} / 0 \mathrm{~h}$ groups, or $1 \mathrm{~h} / 0 \mathrm{~h}$ and $3 \mathrm{~h} / 0 \mathrm{~h}$ groups $(\mathrm{P}>0.05)$. With the expression of ATP5B/TFRC at $0 \mathrm{~h}$ as ' 1 ', the expression of ATP5B decreased significantly at all three time points $[1 \mathrm{~h} / 0 \mathrm{~h}: 0.58 \pm 0.06(\mathrm{P}<0.01) ; 2 \mathrm{~h} / 0 \mathrm{~h}$ : $0.56 \pm 0.09(\mathrm{P}<0.01), 3 \mathrm{~h} / 0$ h: $0.35 \pm 0.08(\mathrm{P}<0.01)$, Fig. $8 \mathrm{C}]$. With the exception of marginal differences in drop trends, this was consistent with the ITRAQ results [1 h/ $0 \mathrm{~h}: 0.59 \pm 0.10$ $(\mathrm{P}<0.01) ; 2 \mathrm{~h} / 0 \mathrm{~h}: 0.73 \pm 0.14(\mathrm{P}<0.05), 3 \mathrm{~h} / 0 \mathrm{~h}: 0.42 \pm 0.06$ $(\mathrm{P}<0.01)]$. There was no statistically significant difference between $1 \mathrm{~h} / 0 \mathrm{~h}$ and $2 \mathrm{~h} / 0 \mathrm{~h}$ ( $\mathrm{P}>0.05)$, however, the expression of ATP5B decreased significantly at $3 \mathrm{~h} / 0 \mathrm{~h}$ compared with that at $2 \mathrm{~h} / 0 \mathrm{~h}$ and $1 \mathrm{~h} / 0 \mathrm{~h}(\mathrm{P}<0.05)$. With the expression of FGG/TFRC at $0 \mathrm{~h}$ as ' 1 ', it was increased at $2 \mathrm{~h}$ and $3 \mathrm{~h}$ [1 h/0 h: $1.07 \pm 0.21(\mathrm{P}>0.05) ; 2 \mathrm{~h} / 0 \mathrm{~h}: 1.72 \pm 0.21(\mathrm{P}<0.01)$, 3 h/0 h: $1.51 \pm 0.18$ ( $<<0.01$ ), Fig. 8D]. Although the expression of FGG was elevated at all three time points, it differed from the results of ITRAQ [1 h/0 h: $2.05 \pm 0.34(\mathrm{P}<0.01) ; 2 \mathrm{~h} / 0 \mathrm{~h}$ : $2.24 \pm 0.42(\mathrm{P}<0.01) ; 3 \mathrm{~h} / 0 \mathrm{~h}: 1.34 \pm 0.31(\mathrm{P}>0.05)]$. With the expression of INTS4/TFRC at $0 \mathrm{~h}$ as ' 1 ', it was increased at all three time points [1 h/0 h: $2.12 \pm 0.41(\mathrm{P}<0.01) ; 2 \mathrm{~h} / 0 \mathrm{~h}$ : $1.99 \pm 0.35(\mathrm{P}<0.01), 3$ h/0 h: $2.20 \pm 0.25(\mathrm{P}<0.01)$, Fig. $8 \mathrm{E}]$ and differed from the ITRAQ results $[1 \mathrm{~h} / 0 \mathrm{~h}: 1.33 \pm 0.21(\mathrm{P}<0.05)$; $2 \mathrm{~h} / 0 \mathrm{~h}: 1.23 \pm 0.17$ ( $\mathrm{P}>0.05), 3 \mathrm{~h} / 0 \mathrm{~h}: 0.50 \pm 0.11(\mathrm{P}<0.05)]$. There were no statistically significant differences between the $2 \mathrm{~h} / 0 \mathrm{~h}$ and $1 \mathrm{~h} / 0 \mathrm{~h}$ groups, $2 \mathrm{~h} / 0 \mathrm{~h}$ and $3 \mathrm{~h} / 0 \mathrm{~h}$ groups, or $1 \mathrm{~h} / 0 \mathrm{~h}$ and $3 \mathrm{~h} / 0 \mathrm{~h}$ groups $(\mathrm{P}>0.05)$. Although the results from 


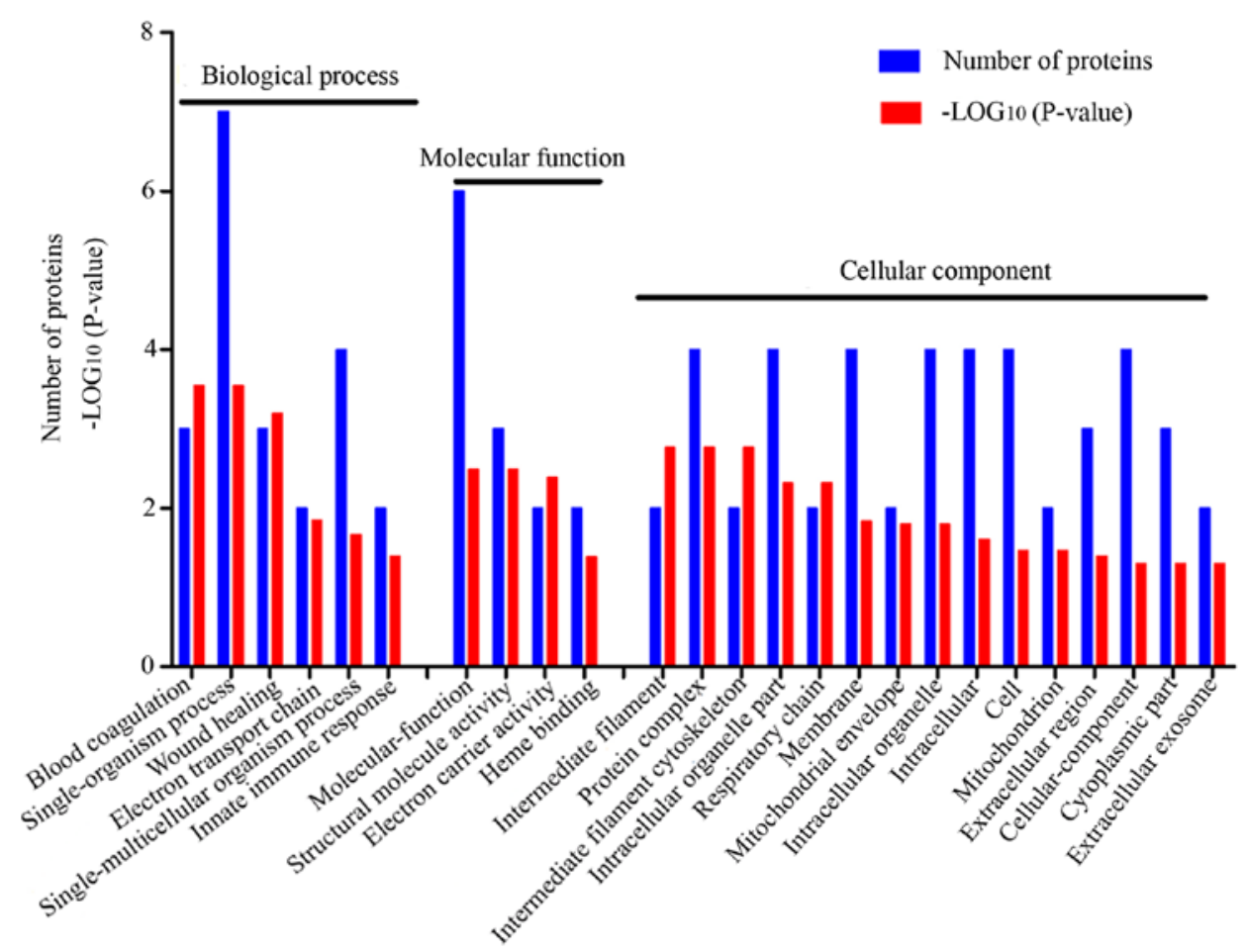

Figure 6. GO enrichment analysis of 19 selected differentially expressed proteins. Data enrichment analysis was performed using the STRING database. It includes the biological process, molecular function, and cellular component. When FDR $<0.05$, the GO term was considered significant. All significant GO terms and respective $-\mathrm{LOG}_{10}(\mathrm{FDR})$ values are presented. GO, Gene Ontology; FDR, false discovery rate.

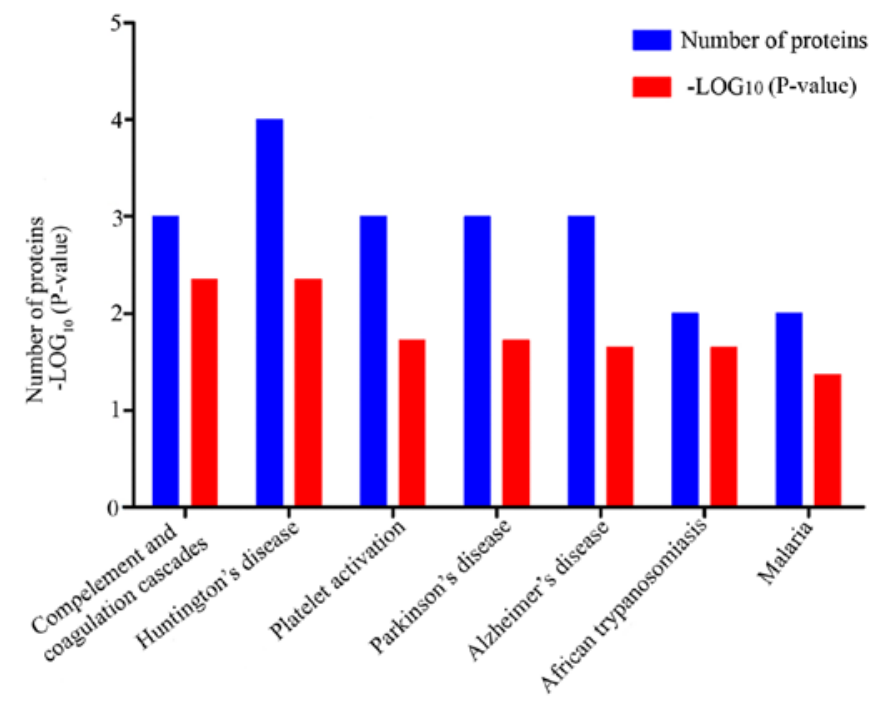

Figure 7. KEGG pathway enrichment analysis of 19 selected DEPs. The KEGG pathway analysis was performed using the STRING database. A pathway was considered significant at a FDR of $<0.05$. All significant pathways are presented. KEGG, Kyoto Encyclopedia of Genes and Genomes; FDR, false discovery rate.

the western blotting did not completely coincide with those of ITRAQ, ATP5B may serve as a biomarker of MI within $3 \mathrm{~h}$.

\section{Discussion}

The diagnosis of AMI is a major issue in cardiology as no specific diagnostic criteria are available for MI within $3 \mathrm{~h}$. In the present study, several DEPs were identified according to ITRAQ technology and 19 were selected based on the GO enrichment analysis.

Among the19 DEPs, Mb has been used as a biomarker clinically, its diagnosis has a high sensitivity after $2 \mathrm{~h}$ of AMI $(27,28)$. Although Mb was one of the clinical biomarkers, its elevation following AMI has high sensitivity but lacks specificity. It is of certain value in eliminating the diagnosis of MI, but is not the preferred standard for clinically determining MI $(29,30)$. However, in a previous study, myoglobin generally rose after 2-4 h of AMI and took 8-12 h to reach its peak (4 h: $169.74 \pm 38.54 \mu \mathrm{g} / 1,12 \mathrm{~h}: 193.42 \pm 47.82 \mu \mathrm{g} / 1,24 \mathrm{~h}: 189.54 \pm 44.63$ $\mu \mathrm{g} / 1,72 \mathrm{~h}: 153.42 \pm 33.75 \mu \mathrm{g} / \mathrm{l})$ (31). The ITRAQ results for $\mathrm{Mb}$ in the present study were similar with these previous data [ITRAQ results: $1 \mathrm{~h} / 0 \mathrm{~h}: 0.88$ ( $\mathrm{P}>0.05), 2 \mathrm{~h} / 0 \mathrm{~h}: 2.54(\mathrm{P}<0.01)$, 3 h/0 h: $1.87(\mathrm{P}<0.01)$ ] (Table I). Furthermore, STRING database analysis revealed the PPI network between these proteins. INTS4, FGG and ATP5B were selected for additional confirmatory experiments. These proteins were selected as only limited data are available with respect to the correlation between these proteins and MI in the current literature, and the corresponding beagle dogs' antibodies were available for purchase. In the present study, data were as follows: ATP5B [1 h/0 h: 0.59 ( $\mathrm{P}<0.01), 2$ h/0 h: 0.73 (P<0.01), 3 h/0 h: 0.42 $(\mathrm{P}<0.01)]$; FGG [1 h/0 h: $2.05(\mathrm{P}<0.05) ; 2$ h/0 h: $2.24(\mathrm{P}<0.05)$, 3 h/0 h: 1.34 (P>0.05)]; INTS4 [1 h/0 h: 1.33 (P<0.01); 2 h/0 h: $1.23(\mathrm{P}>0.05), 3 \mathrm{~h} / 0 \mathrm{~h}: 0.50(\mathrm{P}<0.01)]$ (Table I). The expression of ATP5B was significantly decreased at the three time points. It appears that ATP5B was superior to $\mathrm{Mb}$, as the change in ATP5B appeared earlier than that for Mb. FGG increased significantly at 1 and $2 \mathrm{~h}$, but not at $3 \mathrm{~h}$. INTS 4 increased significantly at 1 and $3 \mathrm{~h}$, from the perspective of speed, FGG and INTS4 were superior to Mb (with the latter increasing 

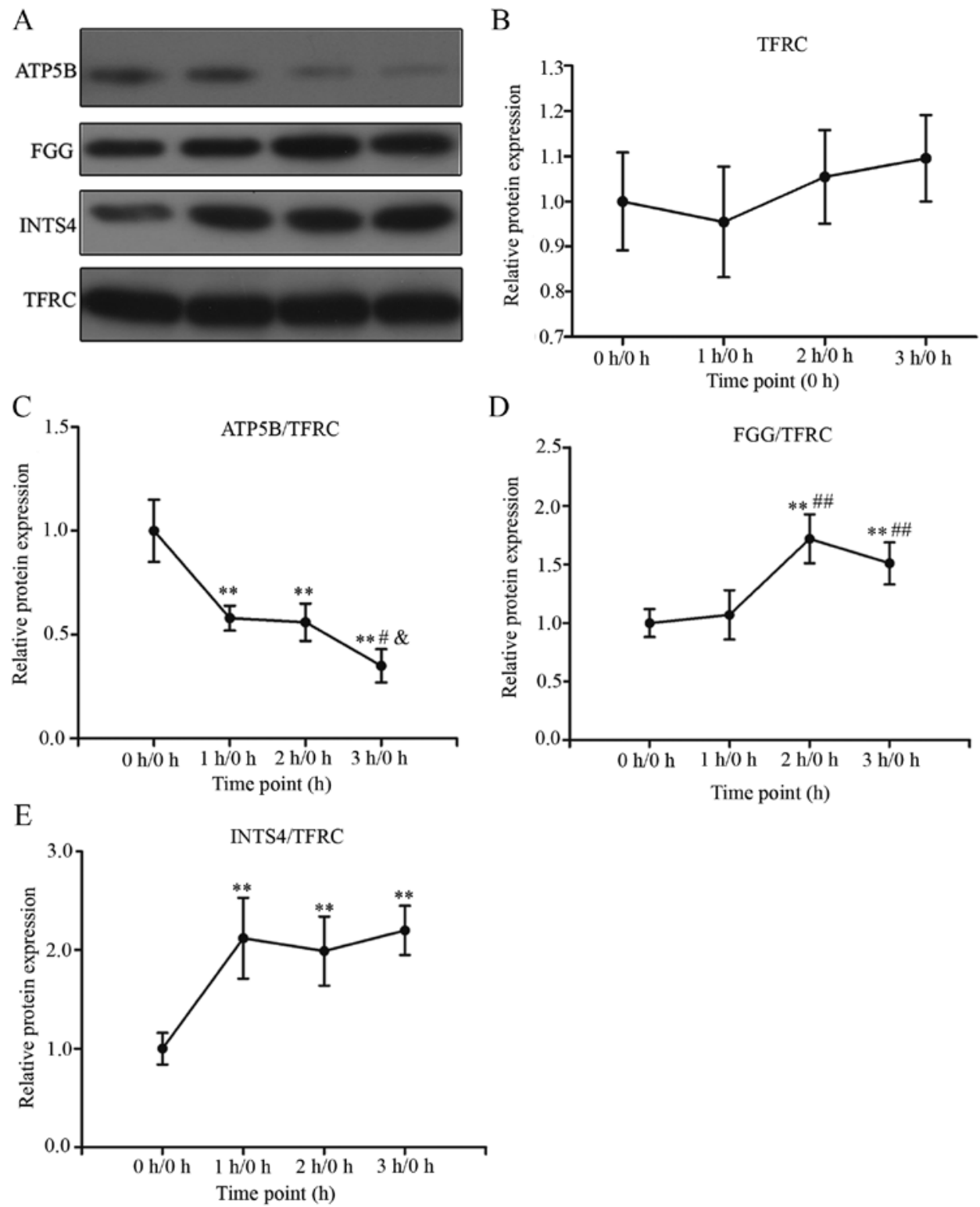

Figure 8. Validation of the expression of TFRC, INTS4, FGG and ATP5B by western blot analysis. The serum levels of TFRC, INTS4, ATP5B and FGG were determined by western blot analysis prior to MI model establishment $(0 \mathrm{~h})$ and following MI model establishment at 1,2 and $3 \mathrm{~h}$ (mean \pm standard error of the mean, $n=10$ ). P-values of multiple groups was calculated using one-way analysis of variance, and pairwise comparison within was performed using the Least Significant Difference test. (A) Representative bands of different proteins at different time points. (B) Relative expression of TFRC at the three time points, $1 \mathrm{~h} / 0 \mathrm{~h}: 0.95 \pm 0.12(\mathrm{P}>0.05) ; 2 \mathrm{~h} / 0 \mathrm{~h}: 1.03 \pm 0.10(\mathrm{P}>0.05), 3 \mathrm{~h} / 0 \mathrm{~h}: 1.05 \pm 0.10(\mathrm{P}>0.05)$. (C) Relative expression of ATP5B at the three time points, $1 \mathrm{~h} / 0 \mathrm{~h}$ : $0.58 \pm 0.06(\mathrm{P}<0.01) ; 2 \mathrm{~h} / 0 \mathrm{~h}: 0.56 \pm 0.09(\mathrm{P}<0.01), 3 \mathrm{~h} / 0 \mathrm{~h}: 0.35 \pm 0.08(\mathrm{P}<0.01)$. (D) Relative expression of FGG at the three time points, $1 \mathrm{~h} / 0 \mathrm{~h}: 1.07 \pm 0.21$ $(\mathrm{P}>0.05) ; 2 \mathrm{~h} / 0 \mathrm{~h}: 1.72 \pm 0.21(\mathrm{P}<0.01), 3 \mathrm{~h} / 0 \mathrm{~h}: 1.51 \pm 0.18(\mathrm{P}<0.01)$. (E) Relative expression of INTS4 at the three time points, $1 \mathrm{~h} / 0 \mathrm{~h}: 2.12 \pm 0.41(\mathrm{P}<0.01) ;$ $2 \mathrm{~h} / 0$ h: $1.99 \pm 0.35(\mathrm{P}<0.01), 3 \mathrm{~h} / 0 \mathrm{~h}: 2.20 \pm 0.25(\mathrm{P}<0.01) .{ }^{* *} \mathrm{P}<0.01$, vs. $0 \mathrm{~h} / 0 \mathrm{~h}$ group; ${ }^{\#} \mathrm{P}<0.05$ and ${ }^{\# \#} \mathrm{P}<0.01$, vs. $1 \mathrm{~h} / 0 \mathrm{~h}$ group; ${ }^{\circledR} \mathrm{P}<0.05$, vs. $2 \mathrm{~h} / 0 \mathrm{~h}$ group. MI, myocardial infarction; ATP5B, ATP synthase F1 subunit $\beta$; FGG, fibrinogen $\gamma$ chain; INTS4, integrator complex subunit 4; TFRC, transferrin receptor 1.

significantly at the second hour), however, the increased expression of $\mathrm{Mb}$ lasted longer and was easier to detect. Finally, it was concluded that ATP5B may be a potential specific diagnostic biomarker for AMI within $3 \mathrm{~h}$. This provided in-depth insight into the occurrence and development of MI, thereby providing a novel direction for MI treatment.

The PPI network revealed that COX2 was at the core of the network. The ITRAQ results showed that the expression of COX2 increased at $1 \mathrm{~h}$ and decreased at $3 \mathrm{~h}$ significantly. COX, a terminal enzyme on the electron transport chain, serves a vital role in the oxidative phosphorylation process of organisms. It can catalyze the transfer of electrons from cytochrome $c$ to oxygen molecules and restore it to water (32). COX in eukary- otes consists of 13-15 subunits; consecutively, the prokaryotic COX contains 3-5 subunits. Subunits 1-3 are encoded by mitochondrial DNA, which are highly conserved sequences and known as core subunits. However, only subunits 1 and 2 can exert complete electron transport activity $(33,34)$. As a key enzyme in energy metabolism, the functional impairment of COX is associated with numerous neurological diseases and tumors, including Alzheimer's disease $(35,36)$, encephalomyopathy (37), muscular dystrophy (38) and colorectal cancer (39). Previous studies have examined the connection between COX2 and MI. Chen et al found that diminazene, an antiparasitic drug, significantly reduced the expression of COX2 and the infarct area (40). Kim et al revealed that 

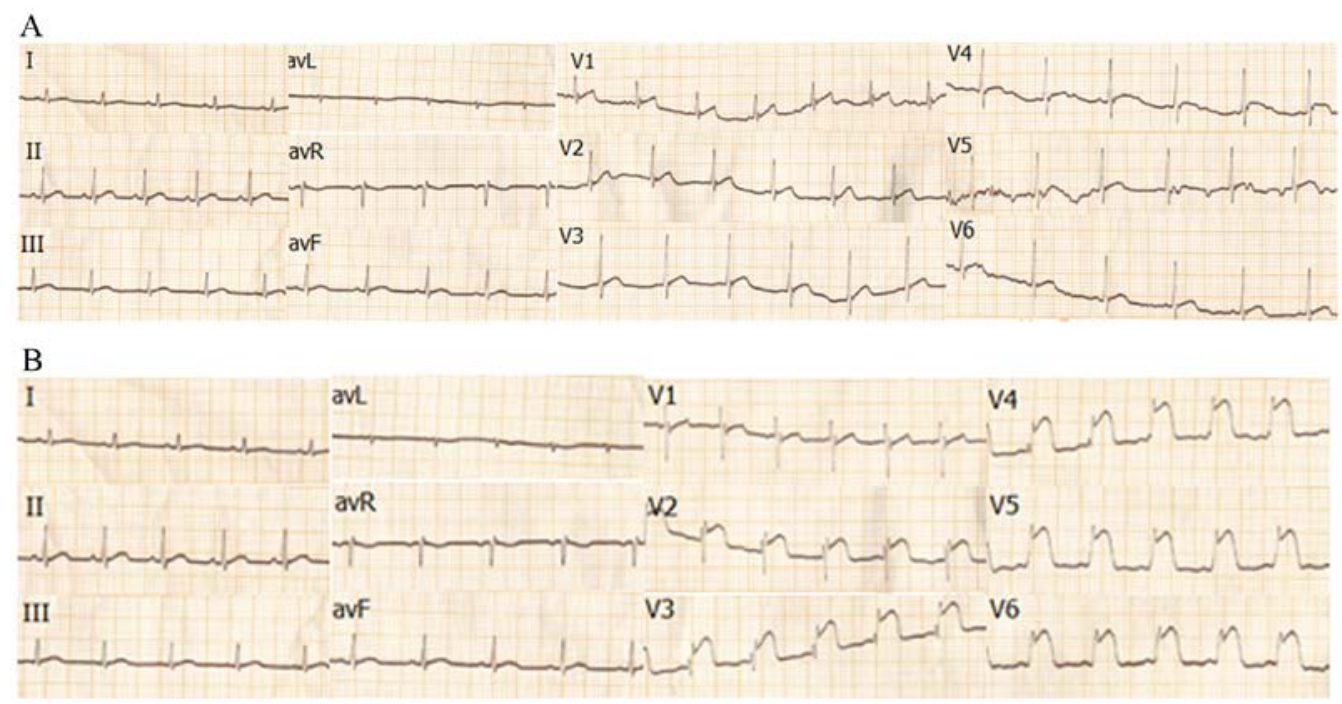

Figure 9. ECG of beagle dogs pre-MI (0 h) and post-MI (3 h). Adapted from Ref (62). (A) ECG of beagle dogs prior to surgery. There was no notable abnormality in the ECG of normal beagles. (B) ECG of beagle dogs at $3 \mathrm{~h}$ post-surgery. The ST segment of beagle dogs between V2 and V6 elevated. ECG, electrocardiogram; MI, myocardial infarction.

ischemic preconditioning (IPC) exerted a protective effect on $\mathrm{MI}$ and ischemia-reperfusion (I/R) injury, and further genetic analysis revealed that most differentially expressed genes were associated with the generation and transformation of energy. In addition, IPC significantly improved the expression of COX2 and COX3 compared with that in the I/R injury group (41). Due to the lack of COX2 antibodies of beagles, it was not possible to verify the expression of key factors in the present study, therefore, further investigations are essential for elucidating the correlation between MI and COX2 .

Notably, in the present study, the expression of MYO1A increased at the three time points; however, MYO1A was not selected for further experiments due to the lack of beagle MYO1A antibody. MYO1A, also known as brush border myosin I, is one of the most noted monomeric motor proteins. MYO1A is associated with several diseases, including autosomal recessive hearing loss (42), Charcot-Marie tooth disease, and gastroenteric tumors $(43,44)$. It serves a critical role in the interface between membrane and cytoskeleton, contains a motor domain that can bind actin and promote constriction between actin and a tail homology 1 (TH-1) domain connected to the membrane (45); however, currently, the function of the TH-1 domain remains to be fully elucidated. MYO1A is also the most prominent plus-end directed motor, and can bind to MYO6 (the sole minus-end directed motor); both motors exert opposing tension and are required for trafficking and ion transport on the brush border (46). Currently, there are no reports describing the association between MYO1A and MI. The change in MYO1 within $3 \mathrm{~h}$ of MI requires further investigation.

The integrator complex is a newly identified multifunctional protein complex. It contains at least 12 subunits (INTS1-INTS12). Takata et al found that the INTS4 was required for the integrity of Cajal bodies (47). The Cajal body is a complex intranuclear organelle that is crucial for the production of snRNP, maintenance of telomere length and proliferation of cells (48). Other studies have indicated that Cajal bodies are involved in the occurrence and development of tumors $(49,50)$. The association between MI and INTS4 remains to be fully elucidated. The ITRAQ results found that the expression of INTS 4 increased at $1 \mathrm{~h}$ and decreased at $3 \mathrm{~h}$ significantly. However, the western blotting revealed that INTS4 increased at the three time points, and further investigations with large sample sizes are required.

ATP5B encodes the expression of ATP synthase subunit $\beta$ that catalyzes the rate-limiting step in ATP synthesis. It is the key protein in the oxidative phosphorylation pathway. The overexpression or silence of ATP5B can influence not only the energy metabolism but also the other pathophysiological process. Zuo et al found that the expression of ATP5B increased in patients with asthma, and may be the vital factor of airway remodeling (51). Xu et al found that during the liver surgery-induced hepatic I/R injury, the expression of ATP5B was decreased. These studies concluded that ATP5B was regulated by the IPC process and may serve as the protective factor in I/R injury (52). In addition, ATP5B is associated with prostate cancer metastasis (53), colorectal cancer (54), clear cell renal cell carcinoma (55) and female thyroid cancer (56). These studies illustrate that the expression of ATP5B alters significantly in the metabolism of different tumor types. ATP5B may provide a potential direction for the diagnosis and treatment of tumors. However, the relevance of the association between ATP5B and MI has not described previously. The ITRAQ results showed that the expression of ATP5B decreased at all the three time points. In addition, the validation findings were consistent with those of ITRAQ. These results suggested that ATP5B may be a biomarker of MI within $3 \mathrm{~h}$, and the potential mechanisms require further investigation.

Several DEPs (ATP5B, COX2 and CYCS) obtained from the ITRAQ results were closely associated with the function of mitochondria. These DEPs are mainly distributed in the electron transport chain of the inner mitochondrial membrane, suggesting that disordered energy metabolism is the initial pathophysiological characteristic of MI. Several studies have examined the connection between MI and energy metabolism. Wang et al stated that the mitochondrial function was impaired in the ischemic myocardium of rat models. Applying Shenmai 
formula, a traditional Chinese medicine, effectively decreased the damage of mitochondrial function (57). Sun and Yang found that metformin improved the myocardial function of mice with heart failure following MI according to regulation of the expression of SIRT3 and PGC-1 $\alpha$ in the mitochondrial inner membrane (58). However, mitochondrial dysfunction is not unique to $\mathrm{MI}$; energy metabolism barriers can also occur in acute cerebral ischemia (59), renal ischemia (60), liver ischemia (61) and other ischemic diseases. This provides a novel direction in order to understand the process of MI, and further investigations are required.

The sensitivity and specificity of the ischemic process, including ECG and myocardial enzyme measurements were also examined, and the relevant results were published previously (62). It has previously been demonstrated that the changes of myocardial enzymes and cTnI in beagle dogs resembled those in humans; cTnI increased significantly at $6 \mathrm{~h}$ post-surgery $[18.13 \pm 5.09(6 \mathrm{~h})$, vs. $0.02 \pm 0.04 \mu \mathrm{g} / \mathrm{ml}(0 \mathrm{~h}), \mathrm{P}<0.01]$, peaked at $\sim 12 \mathrm{~h}(78.68 \pm 2.08 \mu \mathrm{g} / \mathrm{ml}$, vs. $0 \mathrm{~h}, \mathrm{P}<0.01$, vs. $6 \mathrm{~h} \mathrm{P}<0.01)$, and maintained the peak after $24 \mathrm{~h}(79.12 \pm 0.04 \mu \mathrm{g} / \mathrm{ml}$, vs. $0 \mathrm{~h} \mathrm{P}<0.01$, vs. $6 \mathrm{~h}, \mathrm{P}<0.01$, vs. $12 \mathrm{~h} \mathrm{P}>0.05)$; cTnI in humans began to increase at $2 \mathrm{~h}$ post-MI, peaked at $\sim 12 \mathrm{~h}$ and began to decline at $24 \mathrm{~h}$ post MI (4). Similar results were obtained for the remaining enzymes associated with $\mathrm{MI}$, including aspartate aminotransferase, alanine aminotransferase and CK-MB. In the ECG, the ST segment of the V2-V6 leads in the beagle dogs showed marked elevation at $3 \mathrm{~h}$ post-surgery, which was consistent with the expected blocking of the LAD artery. There was no obvious abnormality in the ECG the of the beagle dogs prior to surgery (Fig. 9A and B). These detections confirmed that the dog MI model established was successful, following surgery, the cardiomyocytes were in an ischemic state. Unfortunately, the ECG and cTnI of beagle dogs was not detected within $3 \mathrm{~h}$ of MI. Details are described in a previous study (62).

ITRAQ technology provides a platform for the examination of protein biomarkers. However, the present study has certain limitations. Firstly, it was not possible to collect a large number of serum samples from MI patients for confirmatory experiments as a majority of the patients suffered MI for $>3 \mathrm{~h}$, and informed consent was not obtained at an appropriate time. In addition, no ITRAQ was performed with normal subjects to compare with normal beagle dogs; only if the observed MI-DEPs are not present in the DEP between human and beagle can they serve as biomarkers in humans. Without any data from human samples from real patients, interpretation of the results presented here requires caution. Furthermore, the ITRAQ results were verified for consistency only with western blotting, and hence, additional investigations are essential for further substantiation.

In conclusion, the present study used proteomic analysis to identify the potential early biomarkers of MI in dogs. The experimental results identified a variety of DEPs, providing novel insight for the diagnosis of early MI. However, the specific pathophysiological mechanisms underlying these DEPs in early-stage MI necessitate further investigation.

\section{Acknowledgements}

The ITRAQ experiment was completed by the Shanghai Genechem company.

\section{Funding}

The present study was supported by the grants from the Major Research and Development Projects for the Zhejiang Science and Technology Agency (grant no. 2017C03034), the Natural Science Foundation of Zhejiang province (Project for Young Scientists, grant no. LQ13H020004), the National Natural Science Foundation of China (grant no. 81500284), the Scientific and Technological Projects for Medicine and Health of Zhejiang Province (grant no. 2015128660) and Zhejiang Medicine and Health Science Technology Projects (grant no. 2014KYB012).

\section{Availability of data and materials}

All data generated or analyzed during this study are included in this published article.

\section{Authors' contributions}

CD and YW analyzed the data and wrote the manuscript. JL was responsible for raising the animals. GZ, XL and HJ were responsible for performing coronary angiography for all dogs. SL was responsible for separating serum. LT was responsible for the conception and experimental guidance of the experiment. All authors read and approved the final manuscript.

\section{Ethics approval and consent to participate}

Ethics approval was obtained prior to the start of the study. All animal procedures were performed in accordance with the Animal Care Committee of Zhejiang Hospital.

\section{Patient consent for publication}

Not applicable.

\section{Competing interests}

The authors declare that they have no competing interests.

\section{References}

1. Menon V and Hochman JS: Management of cardiogenic shock complicating acute myocardial infarction. Heart 88: 531-537, 2002.

2. Gupta ED and Sakthiswary R: Myocardial infarction false alarm: Initial electrocardiogram and cardiac enzymes. Asian Cardiovasc Thorac Ann 22: 397-401, 2014.

3. Wei M, Wu X and Li J: Value of measuring TpP,hs-CRP, CKMB and cTnI in patients with acute myocardial infarction. Chin J Cardiouascular Rev 3: 86-87, 2005.

4. Aldous SJ, Richards AM, Cullen L and Than MP: Early dynamic change in high-sensitivity cardiac troponin $\mathrm{T}$ in the investigation of acute myocardial infarction. Clin Chem 57: 1154-1160, 2011.

5. Young GP, Gibler WB, Hedges JR, Hoekstra JW, Slovis C, Aghababian R, Smith M, Rubison M and Ellis J: Serial creatine kinase-MB results are a sensitive indicator of acute myocardial infarction in chest pain patients with nondiagnostic electrocardiograms: The second Emergency Medicine Cardiac Research Group Study. Acad Emerg Med 4: 869-877, 1997.

6. Latosinska A, Vougas K, Makridakis M, Klein J, Mullen W, Abbas M, Stravodimos K, Katafigiotis I, Merseburger AS, Zoidakis J, et al: Comparative Analysis of Label-Free and 8-Plex iTRAQ Approach for Quantitative Tissue Proteomic Analysis. PLoS One 10: e0137048, 2015. 
7. Zieske LR: A perspective on the use of iTRAQ reagent technology for protein complex and profiling studies. J Exp Bot 57: 1501-1508, 2006.

8. Karp NA, Huber W, Sadowski PG, Charles PD, Hester SV and Lilley KS: Addressing accuracy and precision issues in iTRAQ quantitation. Mol Cell Proteomics 9: 1885-1897, 2010.

9. Tvarijonaviciute A, Gutiérrez AM, Miller I, Razzazi-Fazeli E, Tecles $\mathrm{F}$ and Ceron JJ: A proteomic analysis of serum from dogs before and after a controlled weight-loss program. Domest Anim Endocrinol 43: 271-277, 2012.

10. Niu R, Liu Y, Zhang Y, Zhang Y, Wang H, Wang Y, Wang W and Li X: iTRAQ-Based Proteomics Reveals Novel Biomarkers for Idiopathic Pulmonary Fibrosis. PLoS One 12: e0170741, 2017.

11. Li F, Zhao D, Yang S, Wang J, Liu Q, Jin X and Wang W: ITRAQ-Based Proteomics Analysis of Triptolide On Human A549 Lung Adenocarcinoma Cells. Cell Physiol Biochem 45: 917-934, 2018.

12. Tyanova S, Temu T, Sinitcyn P, Carlson A, Hein MY, Geiger T, Mann M and Cox J: The Perseus computational platform for comprehensive analysis of (prote)omics data. Nat Methods 13 : 731-740, 2016.

13. Chu PG and Weiss LM: Keratin expression in human tissues and neoplasms. Histopathology 40: 403-439, 2002.

14. Chiumiento A, Lamponi S and Barbucci R: Role of fibrinogen conformation in platelet activation. Biomacromolecules 8 523-531, 2007.

15. Dobrovolsky AB, Laguta PS, Guskova EV, Yarovaya EB Titaeva EV, Storozhilova AN and Panchenko EP: Effect of fibrinogen on platelet reactivity measured by the VerifyNow P2Y $Y_{12}$, assay. Biochemistry (Mosc) 81: 439-444, 2016.

16. Gendelman $\mathrm{M}$ and Roth Z: Incorporation of coenzyme Q10 into bovine oocytes improves mitochondrial features and alleviates the effects of summer thermal stress on developmental competence. Biol Reprod 87: 118, 2012.

17. Wu X, Steet RA, Bohorov O, Bakker J, Newell J, Krieger M, Spaapen L, Kornfeld S and Freeze HH: Mutation of the COG complex subunit gene COG7 causes a lethal congenital disorder. Nat Med 10: 518-523, 2004

18. Ponnambalam S, Jackson AP, LeBeau MM, Pravtcheva D, Ruddle FH, Alibert C and Parham P: Chromosomal location and some structural features of human clathrin light-chain genes (CLTA and CLTB). Genomics 24: 440-444, 1994.

19. Kostrominova TY: Role of myokines in the maintenance of whole-body metabolic homeostasis. Minerva Endocrinol 41: 403-420, 2016.

20. Welchen E and Gonzalez DH: Cytochrome $c$, a hub linking energy, redox, stress and signaling pathways in mitochondria and other cell compartments. Physiol Plant 157: 310-321, 2016.

21. Steppich BA, Demetz G, Schulz S, von Wedel J,Pogatsa-Murray G, Braun SL, Stein A, Kastrati A, Schömig A and Ott I: Effects of G-CSF on systemic inflammation, coagulation and platelet activation in patients with acute myocardial infarction. Thromb Res 127: 119-121, 2011.

22. Chan HC, Ke LY, Chu CS, Lee AS, Shen MY, Cruz MA, Hsu JF, Cheng KH, Chan HC, Lu J, et al: Highly electronegative LDL from patients with ST-elevation myocardial infarction triggers platelet activation and aggregation. Blood 122: 3632-3641, 2013.

23. Fliedner SM, Yang C, Thompson E, Abu-Asab M, Hsu CM, Lampert G, Eiden L, Tischler AS, Wesley R, Zhuang Z, et al: Potential therapeutic target for malignant paragangliomas: ATP synthase on the surface of paraganglioma cells. Am J Cancer Res 5: 1558-1570, 2015.

24. Shen XL, Zhang Y, Xu W, Liang R, Zheng J, Luo Y, Wang Y and Huang K: An iTRAQ-based mitoproteomics approach for profiling the nephrotoxicity mechanisms of ochratoxin A in HEK 293 cells. J Proteomics 78: 398-415, 2013.

25. Kuhn J and Binder S: RT-PCR analysis of 5' to 3'-end-ligated mRNAs identifies the extremities of $\operatorname{cox} 2$ transcripts in pea mitochondria. Nucleic Acids Res 30: 439-446, 2002

26. Nordström G, Säljö A and Hasselgren PO: Studies on the possible role of oxygen-derived free radicals for impairment of protein and energy metabolism in liver ischemia. Circ Shock 26: 115-126, 1988

27. Castaldo AM, Ercolini P, Forino F, Basevi A, Vrenna L, Castaldo P, D'Ambrosio V and Castaldo A: Plasma myoglobin in the early diagnosis of acute myocardial infarction. Eur J Clin Chem Clin Biochem 32: 349-353, 1994.

28. Tucker JF, Collins RA, Anderson AJ, Hess M, Farley IM, Hagemann DA, Harkins HJ and Zwicke D: Value of serial myoglobin levels in the early diagnosis of patients admitted for acute myocardial infarction. Ann Emerg Med 24: 704-708, 1994
29. De Winter RJ, Koster RW, Sturk A and Sanders GT: Value of myoglobin, troponin T, and CK-MBmass in ruling out an acute myocardial infarction in the emergency room. Circulation 92 , 3401-3407, 1995

30. McCord J, Nowak RM, McCullough PA, Foreback C, Borzak S, Tokarski G, Tomlanovich MC, Jacobsen G and Weaver WD: Ninety-minute exclusion of acute myocardial infarction by use of quantitative point-of-care testing of myoglobin and troponin I. Circulation 104: 1483-1488, 2001.

31. Chen L: The clinical significance of serum myoglobin, troponin and high sensitivity C-reactive protein levels in the dynamic monitoring of patients with acute myocardial infarction. Anhui Med J 9: 1224-1226, 2012.

32. Kadenbach B and Hüttemann M: The subunit composition and function of mammalian cytochrome $c$ oxidase. Mitochondrion 24: 64-76, 2015.

33. Yoshikawa S and Shimada A: Reaction mechanism of cytochrome c oxidase. Chem Rev 115: 1936-1989, 2015.

34. Yoshikawa S, Shimada A and Shinzawaitoh K: Respiratory conservation of energy with dioxygen: cytochrome $C$ oxidase. Metal Ions Life Sci 15: 89-130, 2015.

35. Lee HJ, Korshavn KJ, Kochi A, Derrick JS and Lim MH: Cholesterol and metal ions in Alzheimer's disease. Chem Soc Rev 43: 6672-6682, 2014

36. Cadonic C, Sabbir MG and Albensi BC: Mechanisms of mitochondrial dysfunction in Alzheimer's disease. Mol Neurobiol 53: 6078-6090, 2016

37. Gurgel-Giannetti J, Oliveira G, Brasileiro Filho G, Martins P, Vainzof $M$ and Hirano $M$ : Mitochondrial cardioence-phalomyopathy due to a novel $\mathrm{SCO} 2$ mutation in a Brazilian patient: Case report and literature review. JAMA Neurol 70: 258-261, 2013.

38. Kostrominova TY, Reiner DS, Haas RH, Ingermanson R and McDonough PM: Automated methods for the analysis of skeletal muscle fiber size and metabolic type. Int Rev Cell Mol Biol 306: 275-332, 2013.

39. Módis K, Bos EM, Calzia E, van Goor H, Coletta C, Papapetropoulos A, Hellmich MR, Radermacher P, Bouillaud F and Szabo C: Regulation of mitochondrial bioenergetic function by hydrogen sulfide. Part II. Pathophysiological and therapeutic aspects. Br J Pharmacol 171: 2123-2146, 2014.

40. Chen J, Cui L, Yuan J, Zhang S, Ma R, Sang H, Liu Q and Shan L: Protective effect of diminazene attenuates myocardial infarction in rats via increased inflammation and ACE2 activity. Mol Med Rep 16: 4791-4796, 2017.

41. Kim HK, Kang SW, Jeong SH, Kim N, Ko JH, Bang H, Park WS, Choi TH, Ha YR, Lee YS, et al: Identification of potential target genes of cardioprotection against ischemia-reperfusion injury by express sequence tags analysis in rat hearts. J Cardiol 60: 98-110, 2012.

42. Talebi F, Ghanbari Mardasi F, Mohammadi Asl J, Tizno S and Najafvand Zadeh M: Identification of Novel PTPRQ and MYO1A Mutations in An Iranian Pedigree with Autosomal Recessive Hearing Loss. Cell J 20: 127-131, 2018.

43. Mazzolini R, Rodrigues P, Bazzocco S, Dopeso H, Ferreira AM, Mateo-Lozano S, Andretta E, Woerner SM, Alazzouzi H, Landolfi S, et al: Brush border myosin Ia inactivation in gastric but not endometrial tumors. Int J Cancer 132: 1790-1799, 2013.

44. Mazzolini R, Dopeso H, Mateo-Lozano S, Chang W, Rodrigues P, Bazzocco S, Alazzouzi H,Landolfi S, Hernández-Losa J, AndrettaE, et al: Brush border myosin Ia has tumor suppressor activity in the intestine. Proc Natl Acad Sci USA 109: 1530-1535, 2012.

45. Mazerik JN, Kraft LJ, Kenworthy AK and Tyska MJ: Motor and tail homology 1 (Th1) domains antagonistically control myosin-1 dynamics. Biophys J 106: 649-658, 2014.

46. Kravtsov DV, Caputo C, Collaco A, Hoekstra N, Egan ME, Mooseker MS and Ameen NA: Myosin Ia is required for CFTR brush border membrane trafficking and ion transport in the mouse small intestine. Traffic 13: 1072-1082, 2012.

47. Takata H, Nishijima H, Maeshima K and Shibahara K: The integrator complex is required for integrity of Cajal bodies. J Cell Sci 125: 166-175, 2012.

48. Machyna M, Heyn P and Neugebauer KM: Cajal bodies: Where form meets function. Wiley Interdiscip Rev RNA 4: 17-34, 2013.

49. Palanca A, Casafont I, Berciano MT and Lafarga M: Reactive nucleolar and Cajal body responses to proteasome inhibition in sensory ganglion neurons. Biochim Biophys Acta 1842: 848-859, 2014.

50. Carrero ZI, Velma V, Douglas HE and Hebert MD: Coilin phosphomutants disrupt Cajal body formation, reduce cell proliferation and produce a distinct coilin degradation product. PLoS One 6: e25743, 2011. 
51. Zuo J, Lei M, Wen M, Chen Y and Liu Z: Overexpression of ATP5b promotes cell proliferation in asthma. Mol Med Rep 16: 6946-6952, 2017.

52. Xu C, Zhang X, Yu C, Lu G, Chen S, Xu L, Ding W, Shi Q and $\mathrm{Li}$ Y: Proteomic analysis of hepatic ischemia/reperfusion injury and ischemic preconditioning in mice revealed the protective role of ATP5 $\beta$. Proteomics 9: 409-419, 2009.

53. Li W, Li Y, Li G, Zhou Z, Chang X, Xia Y, Dong X, Liu Z, Ren B, Liu W and Li Y: Ectopic expression of the ATP synthase $\beta$ subunit on the membrane of PC-3M cells supports its potential role in prostate cancer metastasis. Int J Oncol 50: 1312-1320, 2017.

54. Cai Q, Lin J, Zhang L, Lin J, Wang L, Chen D and Peng J: Comparative proteomics-network analysis of proteins responsible for ursolic acid-induced cytotoxicity in colorectal cancer cells. Tumour Biol 39: 1010428317695015, 2017.

55. Brüggemann $M$, Gromes A, Poss M, Schmidt D, Klümper N, Tolkach Y, Dietrich D, Kristiansen G, Müller SC and Ellinger J: Systematic analysis of the expression of the mitochondrial ATP synthase (Complex V) subunits in clear cell renal cell carcinoma. Transl Oncol 10: 661-668, 2017.

56. Lee HS, Kang Y, Tae K, Bae GU, Park JY, Cho YH and Yang M Proteomic biomarkers for bisphenol A-early exposure and women's thyroid cancer. Cancer Res Treat 50: 111-117, 2018.

57. Wang Y, Zhao Y, Jiang W, Zhao X, Fan G, Zhang H, Shen P, He J and Fan X: ITRAQ-based proteomic analysis reveals recovery of impaired mitochondrial function in ischemic myocardium by Shenmai formula. J Proteome Res 17: 794-803, 2018.
58. Sun D and Yang F: Metformin improves cardiac function in mice with heart failure after myocardial infarction by regulating mitochondrial energy metabolism. Biochem Biophys Res Commun 486: 329-335, 2017.

59. Liu X, Tao Y, Wang F, Yao T, Fu C, Zheng H, Yan Y, Liang X, Jiang $\mathrm{X}$ and Zhang Y: Kudiezi injection mitigates myocardial injury induced by acute cerebral ischemia in rats. BMC Complement Altern Med 17: 8, 2017.

60. Lin M, Li L, Li L, Pokhrel G, Qi G, Rong R and Zhu T: The protective effect of baicalin against renal ischemia-reperfusion injury through inhibition of inflammation and apoptosis. BMC Complement Altern Med 14: 19, 2014

61. Cavalcante FP, Coelho AM, Machado MC, Sampietre SN, Patzina RA, Diniz MA, Chaib E and D'Albuquerque LA: Mechanisms of the beneficial effect of sevoflurane in liver ischemia/reperfusion injury. Acta Cir Bras 30: 749-755, 2015.

62. Jiangjie L, Guangzhong Z, Xiaowei L, et al: Establish an animal model of acute myocardial infarction in Beagle dog via injecting microvulsant ball and thrombin powder in coronary artery. J Clin Cardiol 11: 1058-1062, 2017. Attribution-NonCommercial-NoDerivatives 4.0 International (CC BY-NC-ND 4.0) License. 